\title{
Design Breakdown in Industrialized Construction: Supporting Lean Manufacturing
}

\author{
Helena LIDELÖW ${ }^{1,4}$, Gustav JANSSON ${ }^{2}$ and Emma VIKLUND ${ }^{3}$ \\ ${ }^{1}$ Asst Professor, Division of Timber Engineering, Luleå University of Technology \\ ${ }^{2}$ Asst Senior Lecturer, Division of Construction Engineering, Luleå University of Technology \\ ${ }^{3}$ PhD candidate, Division of Construction Engineering, Luleå University of Technology \\ ${ }^{4}$ Corresponding author's e-mail: helena.lidelow@ltu.se
}

\begin{abstract}
A turn-key commitment towards the client compels the contractor to optimize the entire supply chain from design to delivery of the finished building. Industrialization of residential construction can be accomplished using either an open or a closed platform. In the case of an open platform, the client can greatly affect design solutions and the subsequent production phase. The aim of this research is to explain how design process breakdown into activities and deliveries supports Lean manufacturing in an open platform situation. The most successful industrialized contractor in Sweden was studied through mapping their design process of modular buildings using their visual planning display. Describing the improvement strategy, the visual content, and the standardization efforts in design revealed the support for Lean manufacturing. Analyzing each activity for repetitive elements identified the base for standardization. The conclusion is that design breakdown is a successful method that effectively supports Lean manufacturing and provides a base for standardization in an open platform context.
\end{abstract}

\section{KEYWORDS}

Construction design, construction process, modular building, residential building.

\section{INTRODUCTION}

A turn-key commitment towards the client compels the contractor to optimize the entire supply chain from design through manufacturing and assembly to the delivery of the finished building. If the contractor also governs design, there are great opportunities for improving the design process using work breakdown structures and Lean principles such as visual planning. By using either an open or a closed platform in residential construction it is possible to facilitate a standardized work process. The platform is the collection of contractor' assets reapplied between construction projects to create industrialization. When closed platforms are used, the design process is part of production and is organised using configuration tools based on modularization (Meyer and Lehnherd, 1997). Using an open platform, where the client can pose requirements outside the configurable solution space, poses a challenge since it affects the design planning (Jansson et al., 2014). Design breakdown into activities for an open platform is sparsely studied. There is a need for understanding how the combination of visual planning and experience feedback can enable industrialization of the design process using open platforms. The aim of this research is to explain how design breakdown into activities and deliveries supports Lean manufacturing in an open platform situation. 


\section{FRAME OF REFERENCE}

Lean manufacturing (LM) stems from the Japanese industry and is widely applied to improve manufacturing, with the primary goal to identify and eliminate waste for the entire value chain (Liker, 2003). The need for improved production efficiency in the supply chain puts demands on actors to understand the requirements of their customer's customer and the conditions for their suppliers' supplier (Horvath, 2001). In the implementation of LM tools, techniques and methodologies, Hines et al. (2006) discuss the need for understanding both lean thinking on the strategic level and lean production on the operational level to understand value flow. The development of Last Planner and Look ahead planning, Ballard (2000), resulted in systems for improving the project performance and create a predictable flow in project production. Look ahead planning is described as a master schedule, a look ahead schedule, a look ahead plan and a weekly work plan (Hamzeh et al., 2009). The complexity of identifying the design process is due to the interdependency of activities, ubiquitous design iterations, and the need to continuously replan team clustering design tasks (ibid.).

Continuous improvement towards perfection is at the heart of LM (Liker, 2003). Little is known about the process of capturing production knowledge and developing it as a source for improvement in a house building company (Jansson et al., 2015). In the management of future projects, the long term investments of integrating design and construction competences are created in a tension between short-term efficiency and long-term innovation (Eriksson, 2013). The short-term efficiency focus on project performance and the distributed work practices limits incremental innovation from project experience (Bresnen et al., 2004).

Visual planning is a Lean method to plan and visually communicate streamlined work processes by the interdependencies between activities (Liker, 2003). Companies often use this as the first step of implementation to identify bottlenecks, operational transparency and fast visualization of flow related problems (Olausson and Berggren 2010). Visual planning is implemented by JMAC in the Knowledge Innovation/Visible Planning (KIVP) approach (Tanaka, 2002). Hines et al. (2006) describe the approach as bottom-up, where the participants in the process are the ones to establish the existing process state, and also what and how to improve it. Visual boards are used to communicate the process, progress of projects, and improvement possibilities (Hines and Packham, 2008). Knowledge Innovation refers to the upstream flow of experience feedback and transparency in order to learn and improve the process (Hines et al., 2006). Hines et al. (2006) describe that KIVP can be used to analyse how each activity contribute to fulfil project goals, and also why unscheduled activities occur and whether they should be included in the standardization effort or not. The resolution of activities is difficult to visualise and the use of manual boards and physical artefacts e.g. magnets, gives an overview but could make it difficult to store and share knowledge (Lindlöf and Söderberg, 2011). Daily meetings and the breakdown of activities on boards contributes to the enhancement of operational integration, cross-functional communication and visualisation of potential problems (Gamme and Aschemhoug, 2014; Hines and Packham, 2008). Using a design breakdown structure, the decomposition of goals into activities organised by size, duration and responsibility can be detailed in task descriptions of what, who, when and how (Aartsengel and Kurtoglu, 2013). 


\section{METHODOLOGY}

An inductive case study was conducted at the most successful industrialized contractor in Sweden. The company was chosen due to their extensive work with Lean thinking in the design process as a means to increase efficiency and effectiveness to meet the capacity of their factory production. A case study approach was used since it gives an in-depth and holistic view of the studied case (Merriam, 1994) which is the purpose of this particular study. The improvement strategy and the implementation of the visual planning system were recorded by observations and notes from project meetings in the visual planning room at the company. The implications and relations between design activities were mapped through interviews with two project managers and the Lean coordinator at the company. By using a semi-structured approach in the interviews, it was possible to capture the interviewees' thoughts on the design breakdown process, and to ask follow up questions (Backman, et al., 2012). All interviews were taped and transcribed. The predictability of design planning was discussed using data gathered between 2006-2012 on 62 projects on design time divided by square meters of built area. Further analysis was made against the Lean manufacturing strategy focusing flow in the supply chain perspective.

\section{CASE COMPANY}

The case company produces wood-framed residential buildings including student apartments, rental apartments, condominiums, nursing homes, and living for the elderly. The buildings are factory produced in volumetric modules, which are assembled on the construction site, Figure 1. An open platform containing technical solutions in terms of for example façade systems, building frame, and modular interfaces, is used in all projects to enable non repetitive and unique design solutions. Sales use design-build contracts only. This turn-key commitment has led the company to strive towards optimizing the entire process in order to reach an efficient flow of projects through the production process. The information flow is based on downstream pull and it was earlier identified that the design process represents a bottleneck that limits the tact time of production. This motivated the introduction of Lean thinking in the design process.
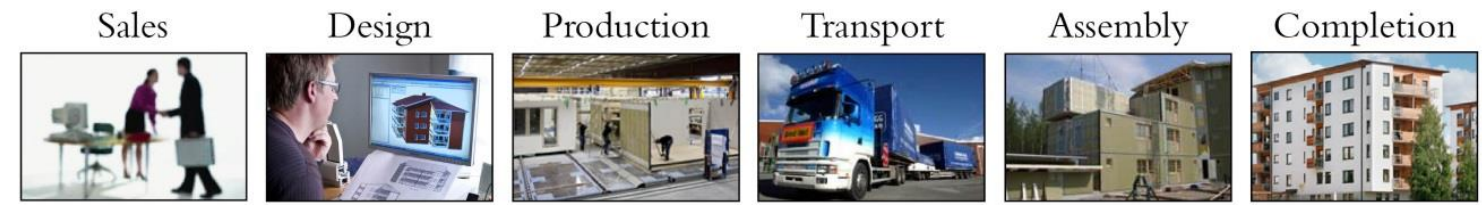

Figure 1. The production chain at the case study company.

\section{RESULTS}

The case company started to work with visual planning through design breakdown in 2000-2002. The initial state was a structure based on a rough time plan where the production start in the factory was the deadline for each design process. Even though some decisive points for time management had been identified, for example the delivery time for windows and stairs, the multiplicity of projects made it difficult to capture and optimize the design process. As a first step towards ensuring better control of the progress, the project managers developed a checklist where they used color codes to identify if the main deliveries were started or not. Even though the list only provided a rough description of deliveries, it served as a means to ensure not to overlook any of them. In 2007, the next step was taken when they made the list visual for everyone in the design process. This was achieved by installing a magnet board, where each 
project was displayed in a row and the deliveries in columns. Green, yellow and red magnets were used to represent status updates in accordance with an improved version of the previous checklist. By having weekly meetings at the magnet board, where everyone got to explain why their deliveries had or had not been finished according to plan, the awareness of relations between deliveries increased in the group. The focus was on whether the deliveries were finished or not, not necessarily on reasons and effects of delays.

To better understand the design process as a flow, the next step was taken in 2010 to map the flow of information and activities, using the KIVP method described in Lean manufacturing e.g. Hines et al. (2006). By tracking how much time the employees spent on each activity and the interdependence between activities it was possible to break down the process. The starting point for the mapping process was the factory start and from there each delivery and activity was traced backwards through the design process by analyzing the pull point for deliveries. Also the activities that are not pure design activities, for example purchasing and some activities performed on the construction site, were included in the design breakdown since they are part of the information flow, Figure 2. Strategic purchasing had a strong influence on time management, and they constituted key milestones while structuring the design process. By adding the dimension of time to the visual content in the magnet board, it was possible to start working towards higher efficiency to match the tact time of the factory. Design breakdown resulted in a standardized design process that worked as the basis for developing the current KIVP-system. The intent was to visualize a general design process and the activities that were common in all projects. By including the employees in refining the KIVP-system while using it, it was possible to have many perspectives on the system. This eventually led to the refined KIVP that is used today (2015), where 400 activities have been specified and scheduled in a 28 week time plan, Figure 2. Each activity in the KIVP contains a number of tasks which are, for most activities, specified in standard operations sheets to ensure that the activities are performed in the same way regardless of who does them, Figure 2. The aim was to ensure that if someone is absent or could not continue with their work task, someone else would be able to continue were the previous person left off. The standard operations sheets have been developed by the employees themselves since the beginning of 2014 in order to ensure that everyone agrees on the content and time of each delivery. The clearer the agreements of deliveries have become, the less built in air has been necessary in the time plan. The KIVP provides a process view of the information flow while the standard operations sheets provide detailed descriptions of how and to whom the information should be delivered.

Standard operations sheets are under constant improvement, led by the team leaders. The team identifies parts of the process that needs improvement e.g. the design of electrical shafts. A subset of the team is assigned the improvement work (which is performed alongside daily operations) and the results are documented in the platform and/or in an improved standard operations sheet. In order to maintain the standardized design process, job observations are performed where the team leaders observe how the standard operations sheets are used in reality. This method has been implemented since the beginning of 2015 and the expectation is that it will give continuity to the process and enable reflection on why deviations from the standard operations sheets are made. The 28 week KIVP template is utilized as a base for all design processes. It is however adapted to each project, since the available time for the design process rarely reaches the full 28 weeks and the projects vary in complexity. The adaption is performed 
manually by the project managers by compressing the time span and regrouping the activities. A risk with this has been identified as overlooking links between activities which might result in delays of the process or missed sub-deliveries. Therefore it has been suggested as an improvement possibility to better visualize the links between activities or to automate the compression of the KIVP.

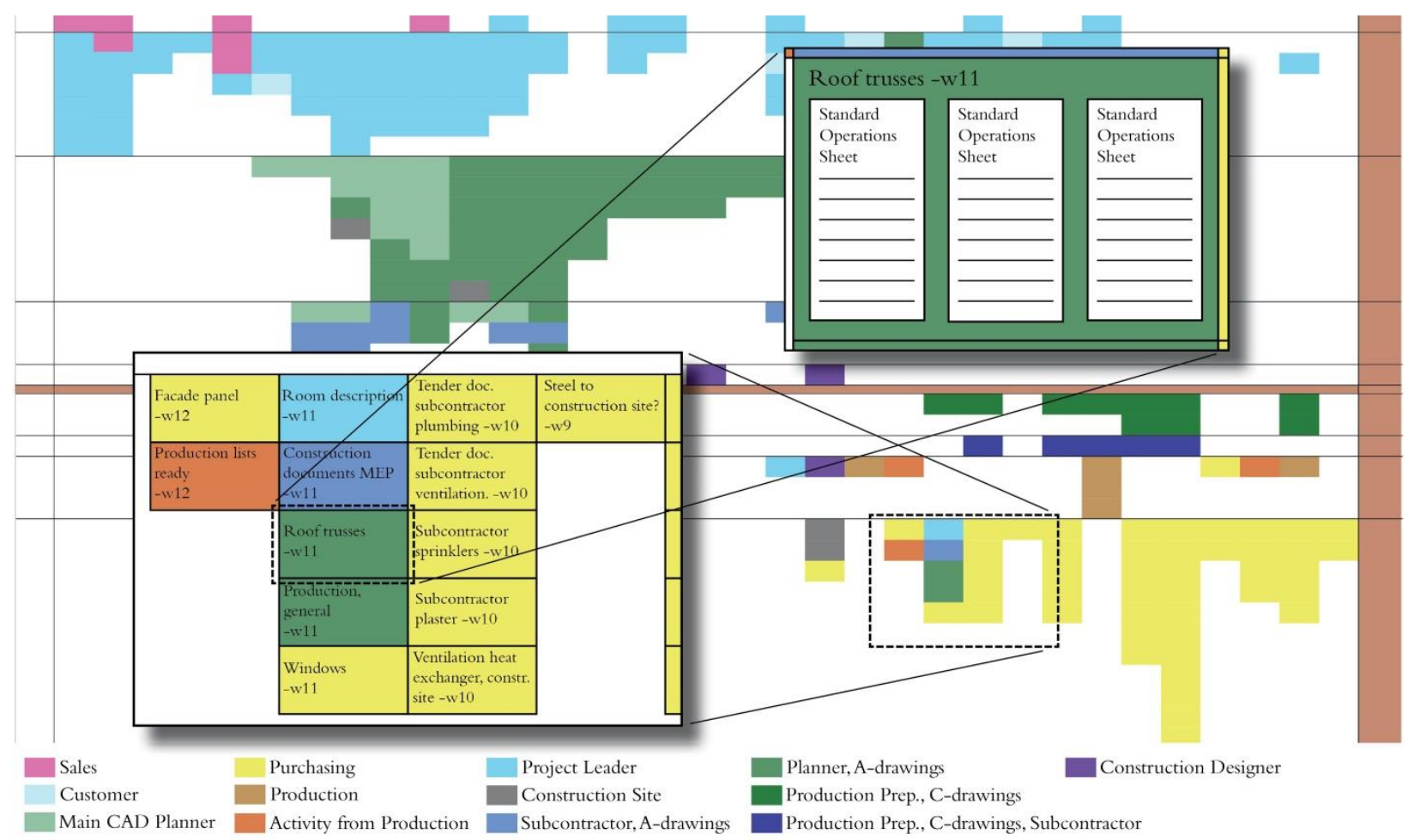

Figure 2. Extract from the case company's KIVP-layout, showing the 28 week time span with responsible functions for each delivery, an example of activities, and how each activity contain standard operations sheets.

The KIVP boards are visualized with magnets which are manually put in place in the visual planning room, Figure 3. This is described as time consuming for the project managers, since they have to clean the magnets and find their right place before the start of each new project. There is a wish amongst the staff to invest in a digitalized system to handle the KIVP boards. Before this investment is made though, the management wants to further refine the implementation of the work method.

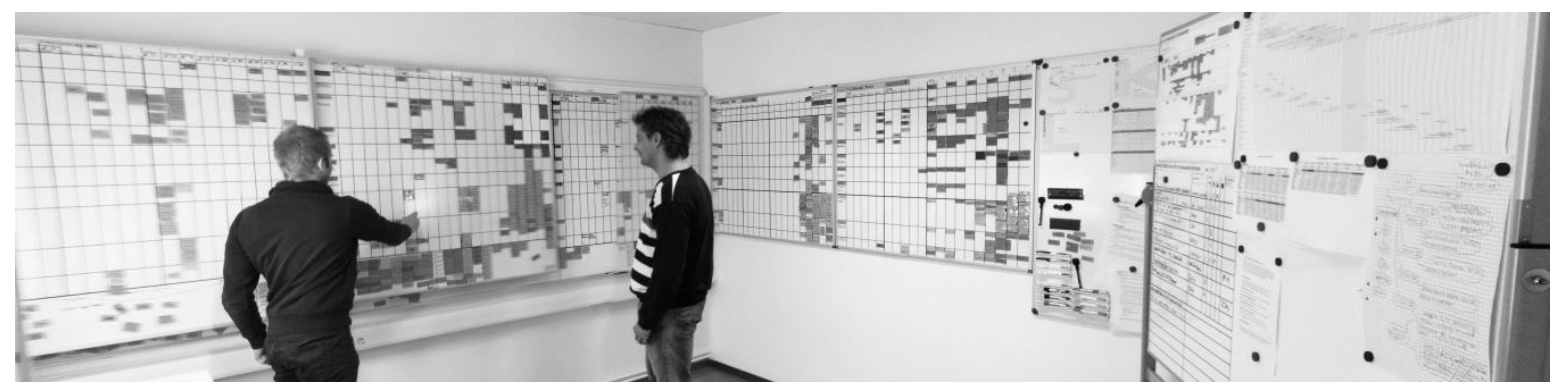

Figure 3. Visual planning room at the case company, using one magnetic board to accommodate each project. Up to seven projects are handled simultaneously in the design process. 
The design team gathers around the KIVP boards each morning to perform a daily review of all projects. The meeting is short; each project leader reports problems and changes in deadlines for their projects. Detailed discussions on solutions are held outside the meeting. Revised drawings are notified to the purchasing and production departments. Changes in bills of materials are reported to the purchasing department. Experience from the factory production and the purchasing department is fed back using an established system that incorporates the entire company. This has led to a better understanding of the design process and the team has experienced that their work is now more homogenous. The KIVP has enabled them to work more structured and instead of fire extinguishing they can now have a preventive approach. By physically updating the magnet board each morning the KIVP has become a living document and deviations surface easily, which is the purpose of this work method.

Since each activity and delivery is specified in the KIVP it is possible to trace delays and faults back to the root cause. This has served as an incentive to reduce the amount of mistakes, since the person who made a mistake will be the one to take responsibility for it. The KIVP has however turned out to serve more as a memory-list and a control document than a means to continuously question the normal state for continuous improvement and the root cause for mistakes. This is expressed as a limitation in today's work methods and one of the improvement areas for the future. One of the interviewees explained that the design team has become well trained in the Visual Planning part regarding planning projects and following up on the progress, but still has some way to go regarding Knowledge Innovation, i.e. experience feedback and questioning of the normal state. In order to further improve the KI-part of the method, the interviewee explained that it is important that the management take the lead. Even though there are still some parts that can be further improved regarding the use of KIVP at the case company, positive results on planning predictability have been shown. Time measurements of 21 projects made between 2006-2012 showed that the mean value of time spent in the design process decreased from 0.70 to 0.62 hours $/ \mathrm{m}^{2}$ and that the standard deviation decreased noticeably.

\begin{abstract}
ANALYSIS
In the case study, two actions interacted to create the KIVP-system: the operational implementation based on worker experience (bottom-up movement) and the strategies from a lean coordinator (top-down movement). Together, they created grounds for continuous improvement and knowledge flow in the organisation. The complexity of breaking down activities into tasks is a continuous work, which was captured in standard operation sheets. This confirms the complexity that Hamzeh et al. (2009) identified about interdependency and constrained activities. The breakdown follows the Last Planner system (Ballard, 2000) of forecasting activities with the use of a 28 week KIVP-layout as a master schedule, 5-7 parallel projects as a look ahead schedule, a project unique KIVP-plan with programmable activities in a look ahead plan and detailed activities and standard operations sheets as a weekly work plan. Lean Manufacturing builds on visualising the flow, making it easy for the participants to understand and improve it (Liker 2003). At the case company, visual planning had several elements to it. Firstly, the magnetic boards visualising the progress of each project in the design phase provide a sense of the flow. Looking across all boards, gives a sense of the situation for the entire design team. The participants at the review meeting were not only the design team, but also their closest internal customers; the purchasing and the factory departments. This is a
\end{abstract}


cornerstone for fast experience feedback of work performance. Another identified value of using a physical room for the daily meetings is to secure the progress of design (Lindlöf and Söderberg 2011). It is also a place to critically analyse the design work against expected goals. In accordance with Hines and Packham's (2008) ideas about the value of a physical control room, the case company had also identified the benefits of getting operational teams involved in a method for understanding the information flow through their design work.

As a base for standardization, daily experience feedback creates a standardised method for updating the process platform for design, purchasing and production in industrialized construction. The standard operations sheets provide a very clear base for industrialization. Once stable, the tasks they describe can be standardized. Care must be taken not to attempt standardization of work tasks that needs to be changeable in the open platform. The long-term benefits of defining and refining activities by experience feedback follow Eriksson's (2013) perspectives on innovation. The difficulties of storing and using experience feedback in production, challenge the organisation to improve the upstream flow of knowledge (Bresnen et al. 2004). The organised flow of daily feedback in the organisation has improved the transparency and speed of problem solving. However, both the Lean coordinator and one of the project managers confirmed the possibility to improve the KIVP by tracking and developing the design process even more. The number and variety of performed projects were important for the definition of activities and work tasks in the standard operation sheets, both to obtain enough resolution and to create flow in the process. Following Gamme and Aschemhoug (2014), the case company utilized the variation of competence for the identification of activities, which in the next step contributed to an increased predictability of the flow. The case study shows, both by measurements and in interviews, how the predictability in the design process can increase. The use of design breakdown explains how the combination of upstream knowledge flow and continuous refinement of design activities contribute to Lean Manufacturing in design.

\section{CONCLUSIONS}

- Design break-down is a successful method to identify and manage an open platform situation that effectively supports Lean manufacturing and provides a base for standardization both on a strategic and an operational level.

- The possibility to standardize the working process enables open platform solutions to be part of the standardization effort.

- By refining the visual planning system through daily use a stable process has been possible to identify which enables design standardization. The 400 activities in the KIVP and their inherent standard operations sheets enables predictability in time management and results even though projects may vary in content and complexity.

\section{ACKNOWLEDGEMENTS}

This work was carried out within the competence centre of Lean Wood Engineering and the research project ATTRACT. We gratefully thank the interviewees at the case study company for their time and inspiration. This work was funded by the Swedish Governmental Agency for Innovation (VINNOVA). 


\section{REFERENCES}

Aartsengel, A., Kurtoglu, S. (2013). "Chapter 9: Create Work Breakdown Structure." Handbook on Continuous Improvement Transformation, Springer, Berlin Heidelberg, 9.1.

Backman, Y., Gardelli, T., Gardelli, V., Persson, A., (2012). "Kapitel 11: Vetenskaplig metod." Vetenskapliga tankeverktyg: tillgrund för akademiska studier. Studentlitteratur, Lund, 11.3.

Ballard, H. G., (2000). The Last Planner System of Product Control. Dr.Thesis. University of Birmingham

Bresnen, M., Goussevskaia, A. and Swan, J. (2004), "Embedding new management knowledge in project-based organizations", Organization Studies, 25(9), 1535-1555.

Eriksson, P.E. (2013). "Exploration and exploitation in project-based organizations: development and diffusion of knowledge at different organizational levels in construction companies", International Journal of Project Management, 31( 3), 333-341.

Gamme, I., Aschehoug, S.H , (2014)."Assessing lean's impact on operational integration", International Journal of Quality and Service Sciences, 6( 2/3), 112 - 123.

Hamzeh, F. R., Ballard, G. and Tommelein, I., (2009). "Is the Last Planner System Applicable to Design? A Case Study." Proceedings for the 17th Annual Conference of the International Group for Lean Construction, Taipei, Taiwan.

Hines, P., Francis, M. and Found, P. (2006). "Towards lean product lifecycle management: a framework for new product development." Journal of Manufacturing Technology Management, 17(7), 866-887.

Hines, P. and Packham, J., (2008). "Implementing Lean New Product Development." IIE Annual Conference Proceedings.

Horvath, L. (2001), "Collaboration: the key to value creation in supply chain management." Supply Chain Management, 6(5), 205-207.

Liker, J.K. (2003), "Section II: The Right Process Will Produce the Right Results." The 14 Principles of Toyota Way: an Executive Summary of Culture Behind TPS, McGraw-Hill, New York, 13.

Lindlöf, L. and Söderberg, B. (2011). "Pros and cons of lean visual planning: experiences from four product development organisations." International Journal of Technology Intelligence and Planning, 7(3), 269-279.

Jansson, G., Johnsson, H., Engström, D. (2014). "Platform use in systems building". Construction Management and Economics, 32(1-2), 70-82.

Jansson, G., Lundkvist, R., Olofsson, T. (2015). "The role of experience feedback channels in the continuous development of house-building platforms." Accepted for publication in Construction Innovation , 15(2).

Meyer, M. and Lehnerd, A. (1997) "Section 3: Platform Strategy." The Power of Product Platforms: Building Value and Cost Leadership, The Free Press, New York.

Merriam., S. B., (1994). "Del 1: Grunder för kvalitativ forskning." Fallstudien som forskningsmetod. Studentlitteratur, Lund, 2.4.

Olausson, D. and Berggren, C. (2010). "Managing uncertain, complex product development in high-tech firms: in search of controlled flexibility." R\&D Management, 40(4), 383-399.

Tanaka, T., (2002). "Efficient Creativity: JIT for Knowledge-Workers.” JMAC Consiel SpA, Milan. 